\title{
Research of Spherical Capsule Feeding System in Hydraulic Pipelines
}

\author{
Deniz Ulusarslan \\ Yildiz Technical University, Department of Mechanical Engineering, 34349, Istanbul, Turkey \\ E-mail: ulusars@yildiz.edu.tr
}

\begin{abstract}
Feeding the material to be transported in the hydraulic pipelines to the system is a subject open to research. The shape, size and density of the material gain importance in the selection of feeding systems. Finding the pressure drops that occur in the flow of spherical ice capsules with water is the basis of the research. However, before the measurements were made, preliminary research was carried out on feeding the capsules to the system during the installation of the experimental set-up. In the experimental study with solid particles with the diameter ratios $(0.8)$ and densities $\left(960 \mathrm{~kg} / \mathrm{m}^{3}\right)$ with smaller dimensions $(\mathrm{d}=\mathbf{0 . 0 1 4 m})$, a pipe construction was obtained in which the solid particles are easily fed into the hydraulic pipeline. Experimental study revealed that lower than predicted pressures occur at the point where solid particles are fed into the pipe. This result means a greater pressure drop than the pressure drops obtained in the venturimeter zone with the same diameter ratio. In this article includes a step-by-step method and a sample pipe geometry for studies that require a low pressure zone in hydraulic pipelines. The pipe geometry designed in this study will form a model for the supply systems in the pipelines. The low pressure region is provided with a pipe and flow arrangement without consuming energy.
\end{abstract}

Keyword- Spherical capsule, Hydraulic pipeline, Pressure gradient, Multiphase flow, Feeding system design

\section{INTRODUCTION}

Many researchers are doing research on capsule flow or slurry flow in hydraulic pipelines. The aim of these studies is to find out how the pressure drops change as the parameters affecting the pressure drops change and to determine the economical pump power suitable for this situation. The velocity and pressure drop measurements were made for single capsule flow with different shapes (spherical, cylindrical, square) with high density $\left(\rho_{\mathrm{c}} / \rho_{\mathrm{w}}=2.0-2.4\right)$. It is the diameter ratio used in the experiments are 0.25 to $0.49(\mathrm{~d} / \mathrm{D})$ and the bulk velocities 1.2 to $3 \mathrm{~m} / \mathrm{s}$ [1]. In some experimental studies [2], [3], measured the pressure drops and velocity values in the flow of the high-density capsule train $\left(\rho_{\mathrm{c}} / \rho_{\mathrm{w}}=7.85\right)$. Capsules are spherical or cylindrical with different type geometries. Investigated the effect of capsule concentration and capsule pipe diameter ratios $(0.80$ and 0.85$)$ on pressure drops. In addition, the effect of pipe bends on the flow and pressure drops in the capsule train water flow was investigated [4],[5].

The flow of capsules with the same density and denser as the carrier fluid in hydraulic pipelines experimentally and numerically were investigated [6],[7]. The study was conducted on vertical and horizontal pipes with a capsule pipe diameter ratio of 0.7 .

The flow of the capsule train called coal $\log$ (diameter of capsule $1.4 \mathrm{~m}$, length of capsule $2.8 \mathrm{~m}$ ) with air theoretically and numerically were examined. The capsules were moved on the rails by the effect of pneumatic thrust and electromagnetic forces [8].

In another study [9], evaluated the relationship between hydraulic and pneumatic systems. Experiments on hydraulic transport in horizontal and vertical pipes were carried out. In the hydraulic and pneumatic transmission of high-density solid particles in vertical and horizontal pipes, the movement mechanisms of the particles were investigated experimentally. Common correlations have been proposed for flow rates and accelerations in hydraulic and pneumatic conveying of particles. Particle's individual movements were measured with a high-speed camera. The particles used in the experiments were given to the measuring line with a piston forced feeder in pneumatic transmission. In the hydraulic part of the experiments, the grains were fed into the vertical pipe from a certain height by the piston force feeding mechanism. It was sent to the measurement area by gravity and water flow from a height of $3 \mathrm{~m}$.

Finding the pressure drops that occur in the flow of spherical ice capsules with water is the basis of the research. With the pipelines where ice capsules are used, both the cooling need will be met and the ice will be used as domestic water after melting. For this purpose, many experimental studies have been carried out with low density spherical capsule train in diameter ratio of 0.8 and the results have been published [10],[11],[12]. In these studies, feeding of spherical capsules to the system in the experimental set was provided by a specially designed elevator. The elevator leaves the capsules to the system from a certain height. In other words, the potential energy of the capsules has been converted into kinetic energy so that it is dragged to the measurement 
point with the water flow. Before starting the experiments with this feeding method, it was focused on designing different feeding systems.

However, before the installation of the pipeline, the life-size capsules had to be fed into the system in the most accurate way. How the capsules can be feeding into the pipeline has been investigated by preliminary experiments. In the preliminary experiments to create the hydraulic pipeline capsule feeding system, it has been noticed that a geometry that allows the formation of a low pressure zone has been obtained. And this study was thought to be an alternative to feeding systems. As a result of the studies, it has been seen that designing a low pressure zone in the capsule feeding section can be a solution. For this purpose, preliminary experiments were carried out in smaller geometries based on dimensional similarity. The results obtained provided information on what were open to study and what were feasible or had to be revised.

This study includes a series of experiments and results aimed at designing a low pressure zone as an alternative to capsule or particulate feeding systems for hydraulic pipeline technologies.

\section{AIMS OF THE EXPERIMENTAL STUDY}

The aim of this study is to provide an alternative to solids feed systems in hydraulic capsule pipelines. In systems where water is used as the carrier fluid, problems may sometimes occur in the delivery of solids to the pipeline. In the test installation designed in two stages, low pressure was created at the solid material supply point and the capsules were sucked into the pipe.

\section{METHOD}

Considering that the pipe where the capsules will enter the system must be constructed as shown in Fig. 1. in order to ensure the capsules to pass to the measurement area without problem and with minimum loss, care was taken to make the diameters of the pipe passing through the measurement area be in ratios that would create vacuum in two sections. It is aimed to easily feed the capsules to the system with the effect of pressure difference and flow velocity. Water heights were read on the piezometer pipers installed on certain parts of the preliminary experiment equipment to calculate the pressures on them. Pressure on the pipe inlet of the experimental equipment (Fig. 1.) was $P_{1}=210 \mathrm{mmwc}$ (millimeter water column) and the pipe's inner diameter was $26 \mathrm{~mm}$, so that the flowrate circulated in the system was found to be $0.000325 \mathrm{~m}^{3} / \mathrm{s}$. The pressure sufficient to create a low pressure zone was determined to be $\mathrm{P}_{2}=100 \mathrm{mmwc}$. Continuity and Bernoulli equations were used for finding that the velocity was $0.6 \mathrm{~m} / \mathrm{s}$ at the pipe inlet section and $1.6 \mathrm{~m} / \mathrm{s}$ at the pressure gradient zone.

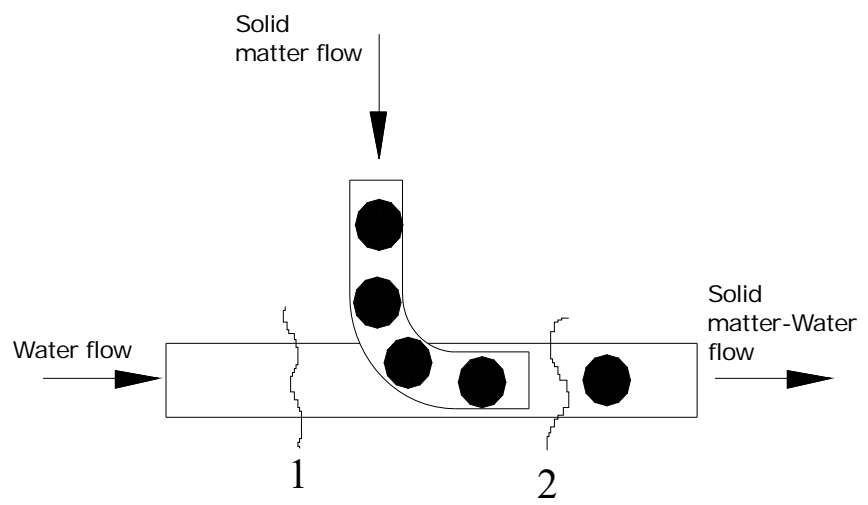

Fig. 1. Area where low pressure is required

The velocities found were used for determining the diameters of the pipes to which the capsules would be delivered and the diameters of the capsules to be used in the next preliminary experiment. It was noticed that in a pipe construction like the one shown in Fig. 1. with a horizontal pipe $26 \mathrm{~mm}$ in diameter, the pipe into which the capsules were delivered must be $20 \mathrm{~mm}$ in diameter to create a vacuum zone in the equipment. After determining the pipe diameter ratios needed to create a vacuum zone, a model was built of polypropylene pipes for the prototype experimental equipment. In the model in question, a wooden capsule with a rounded tip was installed instead of the capsule entry pipe on the horizontal main pipe (Fig. 2.). Inner diameter of the horizontal main pipe was $26 \mathrm{~mm}$, so that capsules $20 \mathrm{~mm}$ in diameter were made. The equipment was fed by a centrifugal pump and was run as a closed circuit. The volume of the water that circulated the system was adjusted by means of a flowrate adjustment valve. 


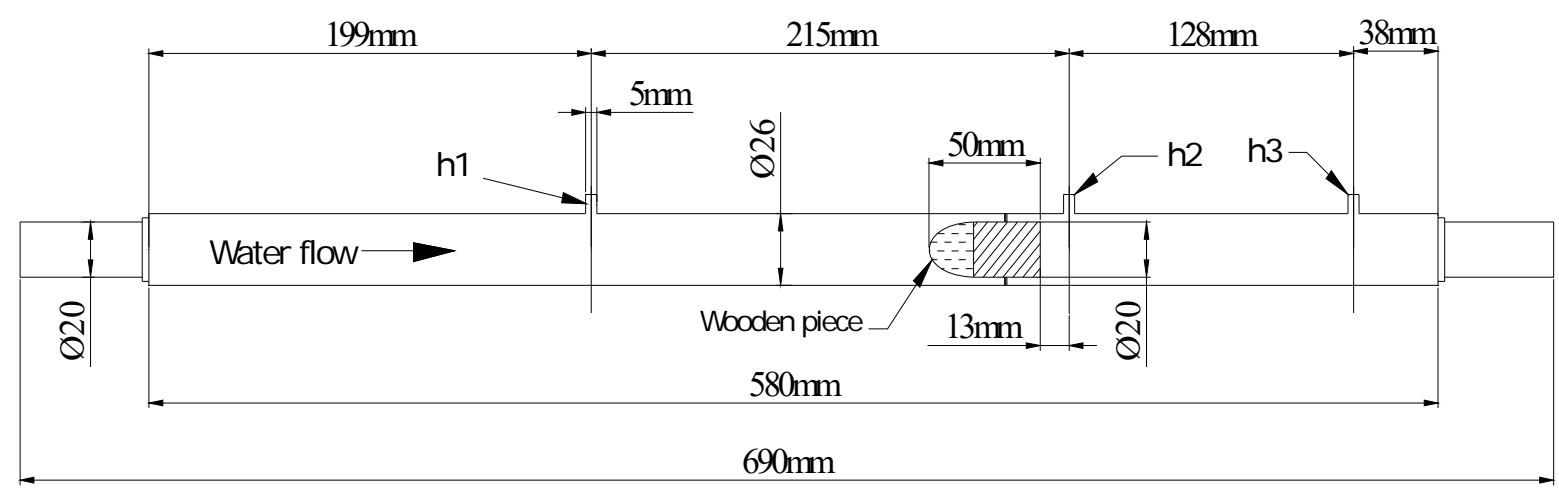

Fig. 2. Preliminary stage of design $\left(\mathrm{h}_{1}, \mathrm{~h}_{2}, \mathrm{~h}_{3}\right.$ piezometric pipes)

In order to observe the pressure gradients, piezometric pipes (inner diameter $6 \mathrm{~mm}$ ) were installed on holes drilled at regular intervals on the horizontal pipe and piezometric load values were read on each hole $\left(h_{1}, h_{2}, h_{3}\right)$. Water levels were measured on the piezometric pipes corresponding to different flowrates and the necessary calculations were made.

The measurements made and the values calculated are given in Table I. This table shows that pressure gradient occurred on two measurement points. Taking the pressure ratios into account, it was calculated that the results obtained would make up the energy losses that arose in the experimental equipment.

It was measured that the pressure gradient was $0.53 \mathrm{mwc}$ (meter water column) and the flowrate that circulated the system was $0.000325 \mathrm{~m}^{3} / \mathrm{s}$. Surface area of the ring that remains between the capsule and the pipe wall was calculated to find the velocity within the ring. Thus, the experimental sudden expansion loss coefficient was found.

TABLE I

The Results Found According to the Pipe Design in Fig. 2

\begin{tabular}{|c|c|c|c|c|c|c|c|c|c|c|}
\hline $\begin{array}{c}\text { Meas. } \\
\text { No. }\end{array}$ & $\begin{array}{c}\mathbf{h}_{1} \\
(\mathrm{mmWC})\end{array}$ & $\begin{array}{c}\mathbf{h}_{2} \\
(\mathrm{mmWC})\end{array}$ & $\begin{array}{c}\mathbf{h}_{3} \\
(\mathbf{m m W C})\end{array}$ & $\begin{array}{c}\mathbf{h}_{1}-\mathbf{h}_{2} \\
(\mathrm{mmWC})\end{array}$ & $\begin{array}{c}\mathbf{h}_{3}-\mathbf{h}_{2} \\
(\mathrm{mmWC})\end{array}$ & $t(s)$ & $\mathbf{Q}\left(\mathrm{m}^{3} / \mathrm{s}\right)$ & $\begin{array}{c}V_{1} \\
(\mathrm{~m} / \mathrm{s})\end{array}$ & $\begin{array}{c}\mathrm{V}_{2} \\
(\mathrm{~m} / \mathrm{s})\end{array}$ & $\begin{array}{c}\mathrm{V}_{3} \\
(\mathrm{~m} / \mathrm{s})\end{array}$ \\
\hline 1 & 1200 & 430 & 670 & 770 & 240 & 13 & 0.0005769 & 1.086 & 4.034 & 3.4 \\
\hline 2 & 1170 & 420 & 660 & 750 & 240 & 13.582 & 0.0005522 & 1.04 & 3.97 & 3.329 \\
\hline 3 & 1070 & 370 & 590 & 700 & 220 & 14.194 & 0.000528 & 0.995 & 3.836 & 3.225 \\
\hline 4 & 920 & 290 & 480 & 630 & 190 & 15.153 & 0.000494 & 0.932 & 3.636 & 3.08 \\
\hline 5 & 780 & 210 & 390 & 570 & 180 & 15.809 & 0.000474 & 0.893 & 3.46 & 2.9 \\
\hline 6 & 670 & 150 & 310 & 520 & 160 & 17.468 & 0.000429 & 0.8 & 3.292 & 2.77 \\
\hline 7 & 480 & 50 & 180 & 430 & 130 & 19.528 & 0.000384 & 0.723 & 2.99 & 2.53 \\
\hline
\end{tabular}

Since the diameters of the pipe and of the capsules were known, theoretical sudden expansion loss coefficient was taken from the table. As a result, a ratio of 0.41 was found between the experimental sudden expansion loss coefficient and the theoretical sudden expansion loss coefficient. This ratio is adapted to the pipe diameters of the actual test equipment to calculate the energy loss caused by the experimental instantaneous expansion loss coefficient.

The necessary calculations were made by using Bernoulli and continuity equations to find that the pressure at the pump outlet made up the loss on the one hand and was sufficient for the pressure gradient measurement area.

In Table I, the water heights read on the $h_{1}, h_{2}, h_{3}$ piezometer pipes, $t$ time in seconds, $Q$ volumetric flow rate, $\mathrm{V}_{1}, \mathrm{~V}_{2}, \mathrm{~V}_{3}$ are the velocity values calculated at the measurement points 1,2 and 3 , respectively. 


\section{TEST SET-UP}

Taking into consideration the pipe diameters for the vacuum zone which the preliminary experiments aimed to create, the equipment shown in Fig.3. was built. To approximate real-life conditions, capsules made of polyethylene having a density $\left(0.96 \mathrm{~g} / \mathrm{cm}^{3}\right)$ lower than that of water were used in the experiments.

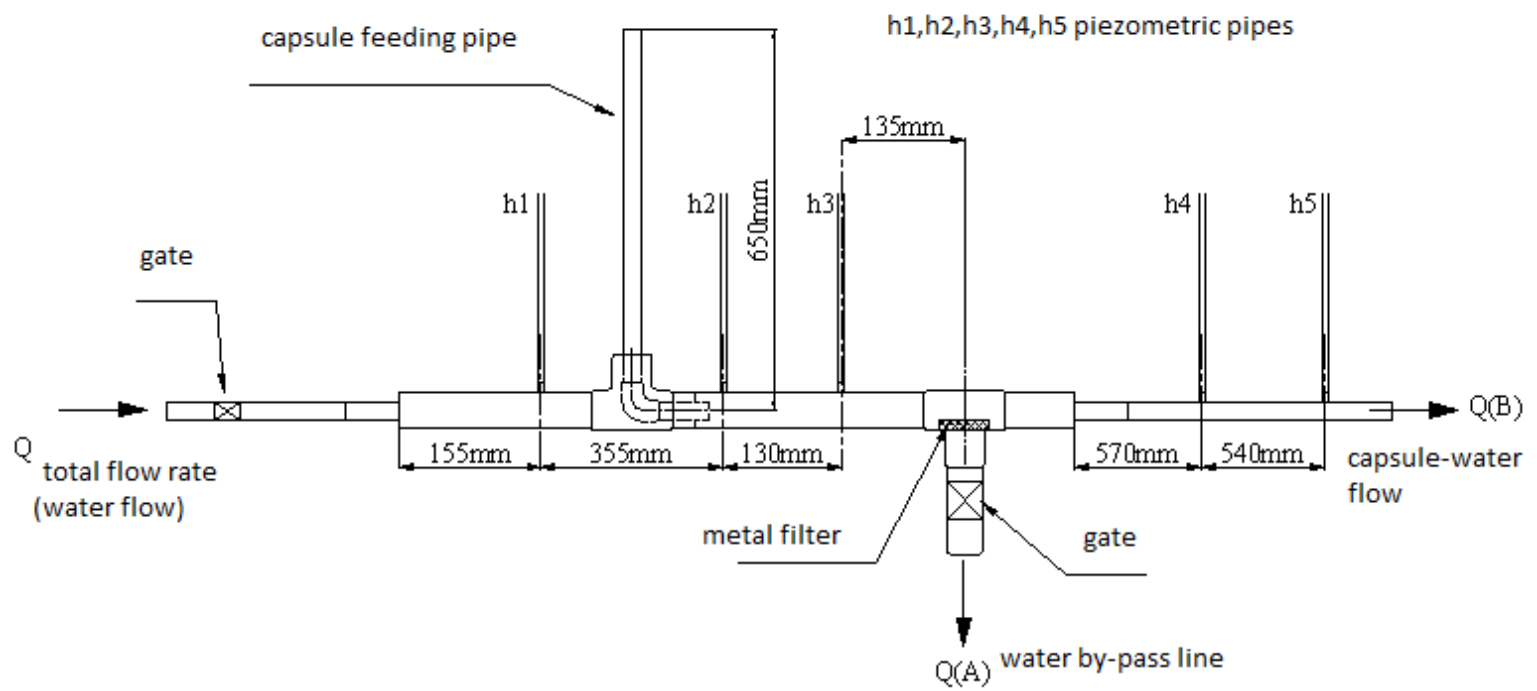

Fig. 3. Pipe and mixture flow design for low pressure zone

The stages of the experiment are listed below:

1) Water inlet and water outlet points of the installation are closed and water is supplied to the pipeline where static pressure will be measured from the hose where the capsules are supplied.

2) A certain water head has been provided in the piezometer pipes and in the hose where the capsules are supplied. When the height values are combined, the resulting horizontal axis has been accepted as the reference line.

3) In order for the measurements to be accurate, the plastic hose connected to the valve that enables water in the $\mathrm{Q}_{\mathrm{A}}$ flow to be taken has been cancelled. Since the water must fall free, a drain line and a tank are placed under the valve.

4) The water inlet and outlet points of the installation are reopened and released to the water inlet.

5) When the installation is started, the amount of water pumped by the pump is adjusted with the valve. Taking care to keep the water height read in the hose where the capsules were given to the reference line, the amount of water drawn with the $\mathrm{Q}_{\mathrm{A}}$ flow rate was changed each time. The values read on the piezometer pipes were determined by assuming the reference line previously determined as zero.

A vacuum zone was created and the capsules' incorporation to the system was tested. To create approximation of the capsule-water flow, diameter of the capsules was determined to be $14 \mathrm{~mm}$, and the inner diameter of the pipe through which they would pass was determined to be $16 \mathrm{~mm}(\mathrm{~d} / \mathrm{D}=0.875)$.

The capsules were manually delivered in this experiment. A valve installed downstream of the spot where the capsules entered the system was used for designing vacuum in desired ratios. During the experiment, water in different $\mathrm{Q}_{\mathrm{A}}$ flowrates was delivered to the tank through a water discharge pipe. All flowrates were calculated by employing the weighing method.

\section{RESULtS}

The pipe inner diameter to which the piezometric pipe $\mathrm{h}_{1}$ is connected in the inlet section is $26 \mathrm{~mm}$, the pipe inner diameter to which the piezometric pipes $h_{2}$ and $h_{3}$ is connected after the feeding point is $26 \mathrm{~mm}$, the $h_{4}$ and $\mathrm{h}_{5}$ piezometric pipes are connected to the outlet pipeline with an inner diameter of $16 \mathrm{~mm}$. The measurements made and the values calculated are given in Table II. 
TABLE III

The Results Found According to the Pipe Design in Fig. 3

\begin{tabular}{|c|c|c|c|c|c|c|c|c|c|c|c|c|c|c|}
\hline $\begin{array}{c}\text { Number of } \\
\text { measurements }\end{array}$ & $\begin{array}{c}\mathrm{Q}_{\text {(тор.) }} \\
\left(\mathrm{m}^{3} / \mathrm{s}\right)\end{array}$ & $\begin{array}{c}\mathrm{Q}_{\text {(A) }} \\
\left(\mathrm{m}^{3} / \mathrm{s}\right)\end{array}$ & $\begin{array}{c}\mathrm{Q}_{(\mathrm{B})} \\
\left(\mathrm{m}^{3} / \mathrm{s}\right)\end{array}$ & $\begin{array}{c}\mathrm{h}_{1} \\
(\mathrm{mmwc})\end{array}$ & $\begin{array}{c}\mathrm{h}_{2} \\
(\mathrm{mmwc})\end{array}$ & $\begin{array}{c}\mathrm{h}_{3} \\
(\mathrm{mmwc})\end{array}$ & $\begin{array}{c}\mathrm{h}_{4} \\
(\mathrm{mmwc})\end{array}$ & $\begin{array}{c}\mathrm{h}_{5} \\
(\mathrm{mmwc})\end{array}$ & $\begin{array}{c}\mathrm{t}_{(\mathrm{B})} \\
(\mathrm{t})\end{array}$ & $\begin{array}{c}\mathrm{t}_{\mathrm{(A}+\mathrm{B})} \\
(\mathrm{s})\end{array}$ & $\begin{array}{c}\mathrm{h}_{1}-\mathrm{h}_{2} \\
(\mathrm{mmwc})\end{array}$ & $\begin{array}{c}\mathrm{h}_{2}-\mathrm{h}_{3} \\
(\mathrm{mmwc})\end{array}$ & $\begin{array}{c}\mathrm{h}_{3}-\mathrm{h}_{4} \\
(\mathrm{mmwc})\end{array}$ & $\begin{array}{c}\mathrm{h}_{4}-\mathrm{h}_{5} \\
(\mathrm{mmwc})\end{array}$ \\
\hline $\mathbf{1}$ & 0.00027778 & 0.00008041 & 0.00019737 & 45 & 20 & 18 & -75 & -110 & 38 & 27 & 25 & 2 & 93 & 35 \\
\hline $\mathbf{2}$ & 0.00030000 & 0.00010769 & 0.00019231 & 60 & 15 & 12 & -72 & -105 & 39 & 25 & 45 & 3 & 84 & 33 \\
\hline $\mathbf{3}$ & 0.00034091 & 0.00013821 & 0.00020270 & 80 & 20 & 15 & -75 & -110 & 37 & 22 & 60 & 5 & 90 & 35 \\
\hline $\mathbf{4}$ & 0.00037500 & 0.00017763 & 0.00019737 & 90 & 22 & 18 & -60 & -95 & 38 & 20 & 68 & 4 & 78 & 35 \\
\hline $\mathbf{5}$ & 0.00044118 & 0.00020680 & 0.00023438 & 115 & 25 & 20 & -90 & -130 & 32 & 17 & 90 & 5 & 110 & 40 \\
\hline $\mathbf{6}$ & 0.00046875 & 0.00026605 & 0.00020270 & 130 & 35 & 25 & -50 & -90 & 37 & 16 & 95 & 10 & 75 & 40 \\
\hline $\mathbf{7}$ & 0.00062500 & 0.00037500 & 0.00025000 & 200 & 50 & 35 & -60 & -120 & 30 & 12 & 150 & 15 & 95 & 60 \\
\hline
\end{tabular}

It was observed that the velocities reached in the pipe construction of experimental set-up were higher than those reached in the venturimeter section under normal circumstances ( Fig. 4.).

In this way, in pipelines with a pipe construction, a solids suction zone can be provided for any capsule pipe diameter ratio. The system will remain the same, only by changing the diameter ratio, the solid material absorption area can be provided.

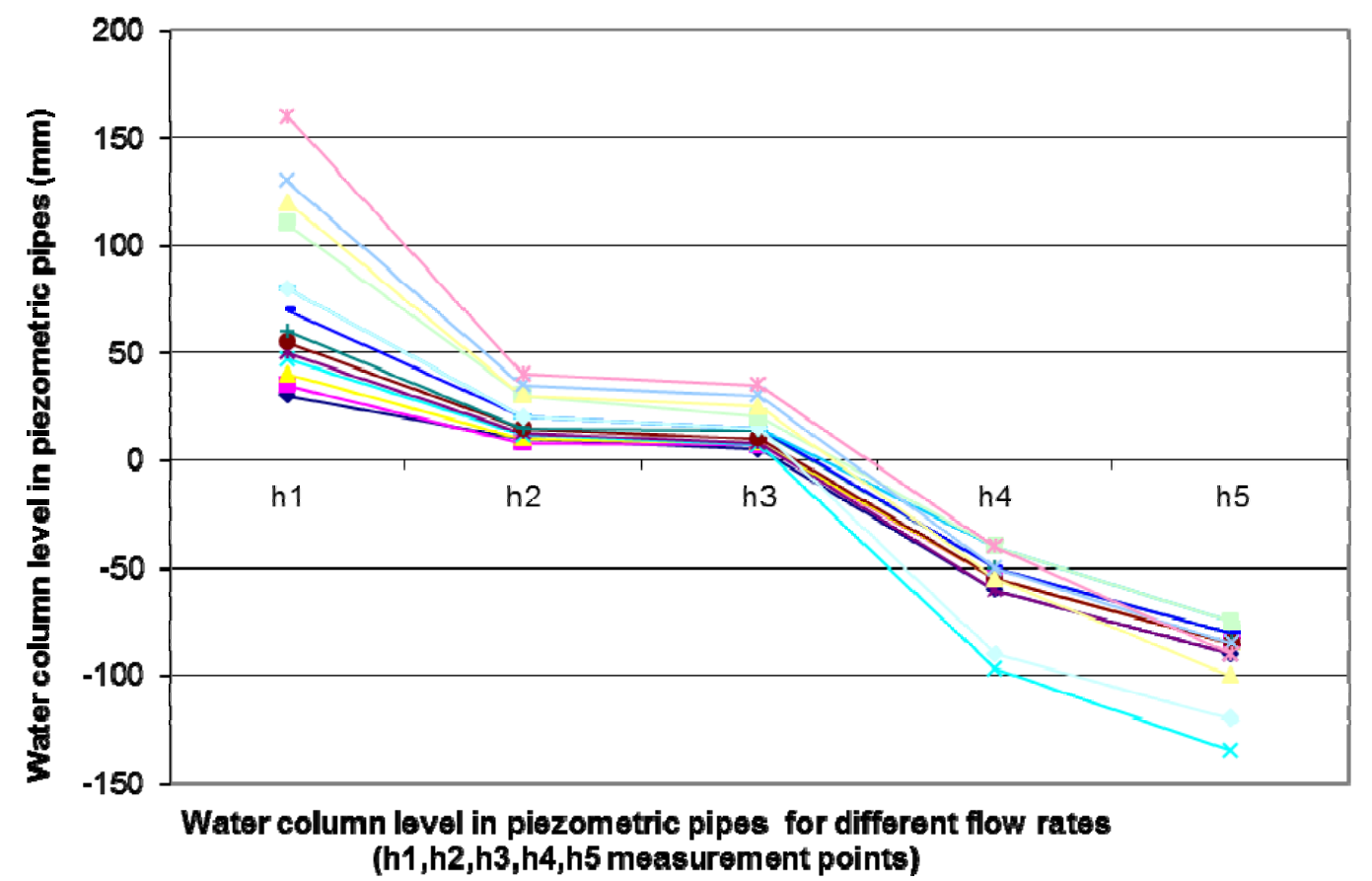

Fig. 4. Static pressures measured in the pipe design in Figure 3

\section{CONCLUSIONS}

In hydraulic pipelines, materials move in the pipe, sometimes in the form of slurry, sometimes in the form of capsules or fine particles. The behaviour of liquid-solid mixture flow in pipes gains importance in horizontal pipes, vertical pipes and pipe fittings. The introduction of solid material (especially with low density) into the pipeline is also a problem in itself. In this study, the results of a research on the capsule feeding system are given. According to the results, a low pressure zone was created in such a pipe geometry to facilitate the passage of capsules to the pipeline.

On the basis of this pipe geometry, higher level experiments should be made to create a vacuum zone in this way. Studies on the numerical solution of this study have begun, and if it complies with experimental data, 
pressure drops that may occur for larger pipe and capsule geometries can be predicted in advance. At the same time, the vacuum zone pipe geometry created by these experiments was a good example of the velocity and pressure changes due to cross-section change in fluid mechanics, except for the orifice and venturimeter. The pipe geometry in which we create low pressure will be an alternative to vacuum pumps, pneumatic blowers and mechanical feeders.

The energy spent on the impeller and spiral feeding systems used in pneumatic and hydraulic conveying lines, as well as on vacuum pumps or high pressure bellows will be eliminated with the designed pipe construction.

\section{NOMENCLATURE}

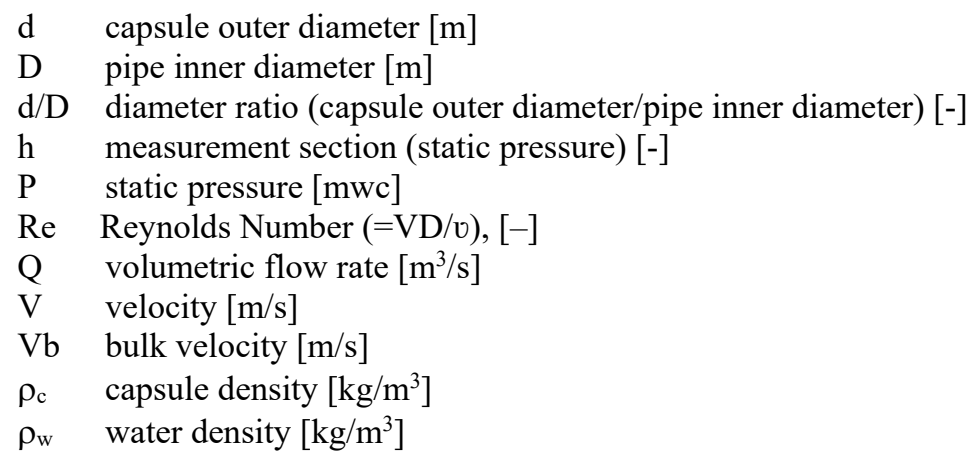

\section{REFERENCES}

[1] V.C. Agarwal, R. Mishra, “ Optimal design of a multi-stage capsule handling multi-phase pipeline”, International Journal of Pressure Vessels and Piping, vol. 75, Issue 1, pp. 27-35, 1998

[2] P. Vlasak., J. Myska, “ Motion of capsules conveyed by liquid in a pipe ”, 1st Conf. on Mechanics. 7,pp. 146-149, 1987.

[3] P. Vlasak, "The pipeline flow of heavy solid capsules", The 4th International Symposium on Underground Freight Transportation by Capsule Pipelines and Other Tube/Tunel Systems, 2005.

[4] P. Vlasak., V. Berman, S. Kril, "Experimental study of capsule flow in bent and inclined pipeline", The 2nd International Symposium on Underground Freight Transportation by Capsule Pipelines and Other Tube/Tunel Systems, 2000.

[5] P. Vlasak, V. Berman,. "A contribution to hydrotransport of capsules in bend and inclined pipeline sections", Handbook of Conveying and Handling of Particulate Solids, p. 521-529, 2001

[6] A. Taimoor, A. Abdualmagid, M. Rakesh, "Effect of capsule shape on hydrodynamic characteristics and optimal design of hydraulic capsule pipelines", Journal of Petroleum Science and Engineering, vol.161, p. 390-408, Feb. 2018.

[7] A. Taimoor, M. Rakesh, "Computational fluid dynamics based optimal design of hydraulic capsule pipelines transporting cylindrical capsules", Powder Technology, vol. 295, p. 180-201, July 2016.

[8] M. Turkowski, M., Szudarek, "Pipeline system for transporting consumer goods, parcels and mail in capsules", Tunnelling and Underground Space Technology, vol. 93, p. 1-13, November 2019.

[9] N. Santo, D. Portnikov, H. Kalman, "Experimental study on particle velocity and acceleration length in pneumatic and hydraulic conveying systems", Powder Technology, vol. 383, p. 1-10, May 2021.

[10] D. Ulusarslan, "The investigation of sphere with density equal to that of the ice and water mixture flow in circular cross section pipes", Ph.D. Thesis, Yildiz Technical University, Istanbul, Turkey, 2003.

[11] D. Ulusarslan, I. Teke, "An experimental investigation of the capsule velocity, concentration rate and the spacing between the capsules for spherical capsule train flow in a horizontal circular pipe", Powder Technology, vol. 159, p. 27-34, 2005.

[12] D. Ulusarslan, I., Teke, "An experimental determination of pressure drops in the flow of low density spherical capsule train inside horizontal pipes", Experimental Thermal and Fluid Science, vol. ,30,p. 233-241, 2006.

\section{AUTHOR PROFILE}

Deniz Ulusarslan graduated from Uludag University Mechanical Engineering Department with a 3rd degree (1991). She received her Master of Engineering degree (1994) from Balikesir University. She received the title of Doctor Engineer from Yildiz Technical University (2003).

Currently, she has been working as an Associate Professor at Yildiz Technical University, Department of Mechanical Engineering since 2015. Her main research interests include; solid-liquid multiphase flows, capsule flow, hydraulic transport, fluid mechanics, heat transfer, solar energy technologies, renewable energy systems. Author ORCID Number: 0000-0002-3762-658X 